\title{
A Smart Waste Bin for Waste Disposal
}

\author{
Ashwini M P, Meghana S R, Rakshitha D, Sushmitha S, Rummana Firdaus* \\ Department of Computer Science and Engineering, GSSS Institute of Engineering and \\ Technology for Women, Mysuru, India
}

DOI: https://doi.org/10.21467/proceedings.1.16

* Corresponding author email: rummana@gsss.edu.in

\begin{abstract}
Many times, in our city we see that the garbage bins or dustbins placed at public places are overloaded. It creates unhygienic conditions for people as well as ugliness to that Place leaving bad smell. To avoid all such situations, we are going to implement a project called Intelligent bin for waste segregation management. These dustbins are interfaced with ARDUINO UNO microcontroller-based system having Ultrasonic sensor detects the human presence and showing current status of garbage. Design and build a prototype for an automatic open dustbin that can automatically open the lid when it detects the human, using a manual switch and bluetooth we can also able open the lid. Major part of our project depends upon the working of the GSM module. When trash level increases more than $90 \%$ the a message is sent to the concerned authorities that it is filled. The main aim of this project is to reduce human resources and efforts along with the enhancement of a smart city vision.
\end{abstract}

Index Terms- ARDUINO UNO Microcontroller, Ultrasonic sensor, GSM Module, Power supply, Servo Motor, LED, Bluetooth, Switch;

\section{INTRODUCTION}

Following the onset of industrialization and the sustained urban growth of large population centers, the buildup of waste in the cities caused a rapid deterioration in levels of sanitation and the general quality of urban life. The streets became choked with filth due to the lack of waste clearance regulations. Waste management is all the activities and actions required to manage waste from its inception to its final disposal. This includes amongst other things, collection, transport, treatment and disposal of waste together with monitoring and regulation. It also encompasses the legal and regulatory framework that relates to waste management encompassing guidance on recycling etc. The term usually relates to all kinds of waste, whether

(C) 2018 Copyright held by the author(s). Published by AIJR Publisher in Proceedings of the $3^{\text {rd }}$ National Conference on Image Processing, Computing, Communication, Networking and Data Analytics (NCICCNDA 2018), April 28, 2018.

This is an open access article under Creative Commons Attribution-NonCommercial 4.0 International (CC BY-NC 4.0) license, which permits any non-commercial use, distribution, adaptation, and reproduction in any medium, as long as the original work is properly cited. ISBN: $978-81-936820-0-5$ 
A Smart Waste Bin for Waste Disposal

generated during the extraction of raw materials, the processing of raw materials into intermediate and final products, the consumption of final products, or other human activities, including municipal (residential, institutional, commercial), agricultural, and social (health care, household hazardous wastes, sewage sludge). Waste management is intended to reduce adverse effects of waste on health, the environment or aesthetics. This is a project which proposes the solution for the waste removal with the IOT technology incorporated in Arduino.

In our system, the Smart dustbins are connected to the internet to get the real time information of the smart dustbins. In the recent years, there was a rapid growth in population which leads to more waste disposal. So a proper waste management system is necessary to avoid spreading some deadly diseases. Managing the smart bins by monitoring the status of it and accordingly taking the decision. There are number of dustbins are located throughout the city or the Campus

\section{PROPOSED METHOD}

Developing a prototype for an automatic open dustbin that can automatically open the lid when it detects the people who want to throw out their trash. Using manual switch and Bluetooth we can also able to open the lid. If the dustbin is full of trash at the certain level, the lid will not open even when there are people who want to throw out their trash. When trash level increases more than $90 \%$ then we are sending a sms to the owner that it is filled. The bin is also monitored using LED's (green, yellow and red). If the green light is on then the bin empty, if the yellow light is on then the bin is in middle level, if the red light is on then the bin is full.

The main objectives of our proposed system are as follows:

$>$ Monitoring the waste management.

$>$ Providing a smart technology for waste system.

$>$ Avoiding human intervention.

$>$ Reducing human time and effort

$>$ Resulting in healthy and waste ridden environment.

\section{ARCHITECTURE}

A system architecture is the model that defines the structure, behavior, and more views of a system. An architecture description is a formal description and representation of a system, organized in a way that supports reasoning about the structures and behaviors of the system. 


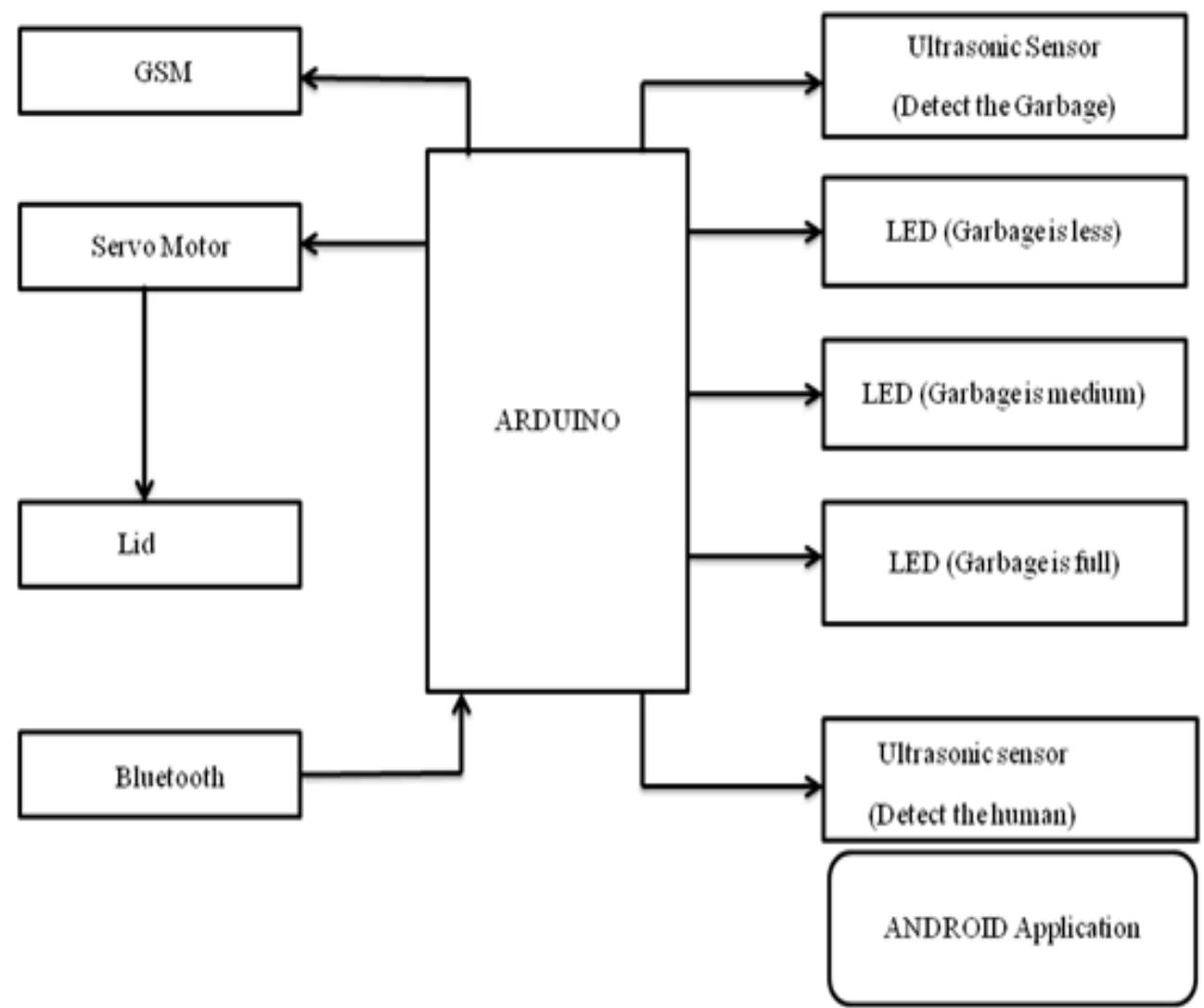

Fig 1: System Architecture

As in Fig 1 the various components integrated in the sbove architecture are:

\section{A. Ultrsonic Sensor}

It is used to detect the distances from obstacles thy col-lision can be avoided. It is based on the echolocation process. Transmitted sound waves bounced back and retrieved with some time difference that helps to calculate the distance. It is shown in Fig 2.

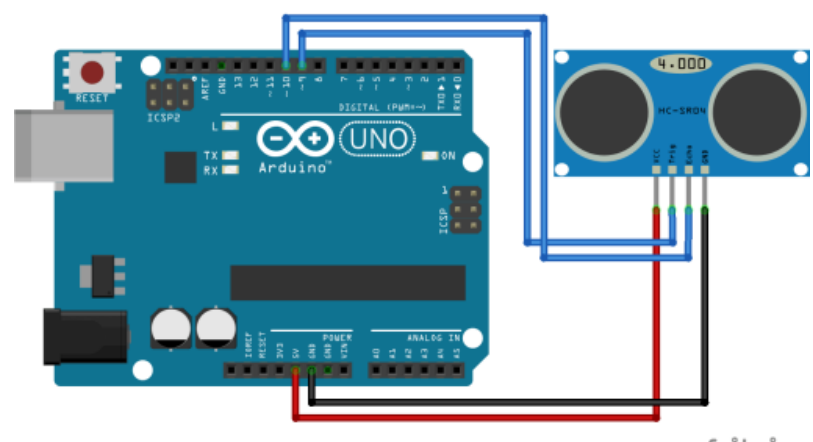

Fig 2: Connection of an Ultrasonic sensor

Proceedings of the $3^{\text {rd }}$ National Conference on Image Processing, Computing, Communication, Networking and Data Analytics (NCICCNDA 2018) 


\section{B. Ardunio UNO}

Arduino is an open-source electronics platform based on easy-to-use hardware and software. Arduino boards are able to read inputs - light on a sensor, a finger on a button, or a Twitter message - and turn it into an output - activating a motor, turning on an LED.

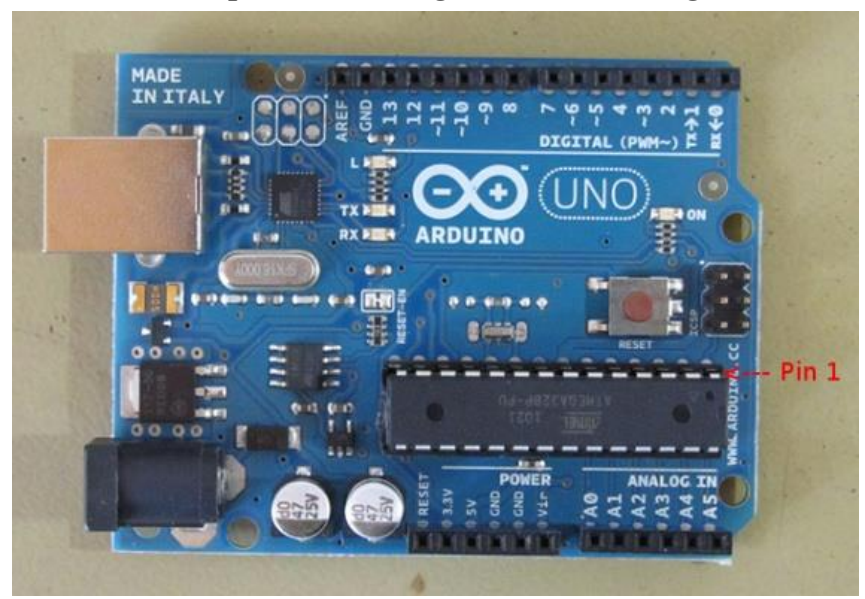

Fig 3:Sample Arduino Uno

\section{GSM Module}

The GSM module sends a message saying that the dust bin is filled along with the position i.e., latitude and longitude of the bin to the garbage collectors number. A notification will be sent to the user's application receiving which the app gets activated. Hence the waste management can be achieved in an efficient way.

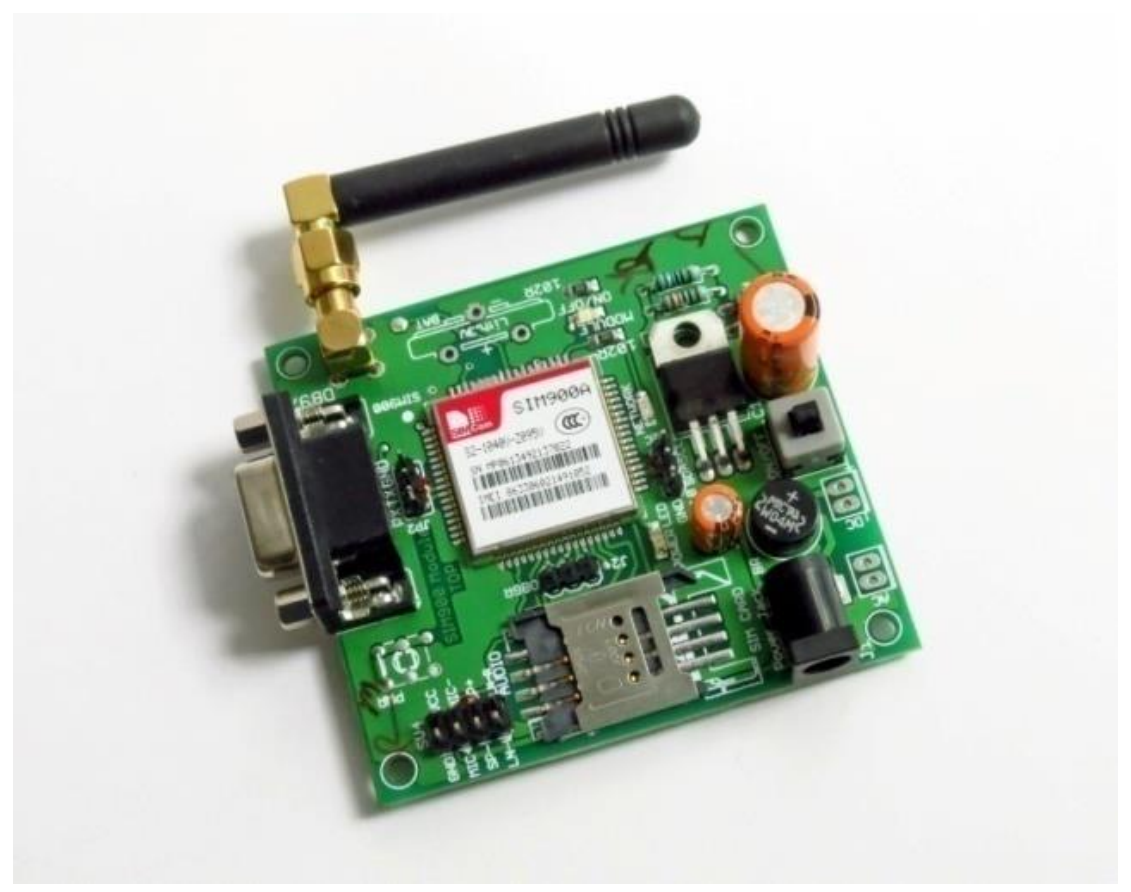

Fig 4: Sample GSM Module 


\section{Status Indicator}

Once the user logs in successfully he would be able to access the information like status and location of the bin. Two LEDs green and red will be placed on the bin. When the bin is filled or if the weight of the waste inside the bin exceeds a threshold value then the red LED is lit up. And the green LED is on when the bin is empty. The overall process information is being displayed on the LCD display.

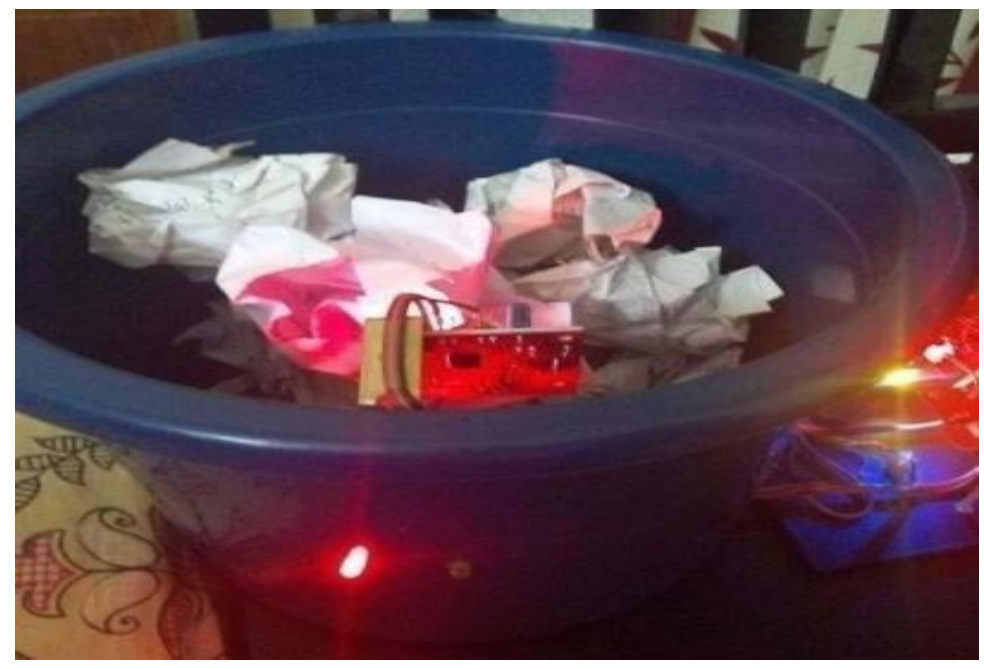

Fig 5: Red LED is on when bin is filled

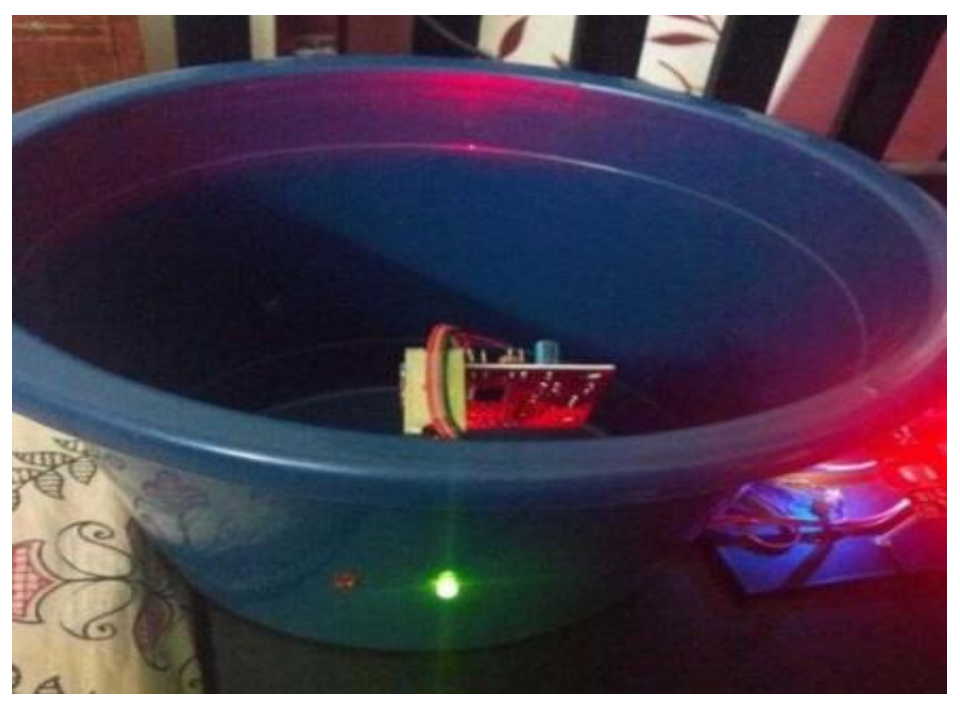

Fig 6: Green LED is on when bin is empty

\section{E. Servo Motor}

Servo Motor is used for automatic opening and closing of bin. The opening and closing of bin can be monitored using an android phone and manually with the help of switch.

Hence the proposed model helps to a great extent in knowing the condition of Waste Bins

Proceedings of the $3^{\text {rd }}$ National Conference on Image Processing, Computing, Communication, Networking and Data Analytics (NCICCNDA 2018) 
In the entire world, waste management is a major challenging one. If it is not properly disposed or cleaned it might lead to inception of diseases and spoil the green environment. There is need of new mechanism to properly dispose the waste. Embedded Technology has been used to provide better garbage disposal method which can be implemented in urban areas. When bin is filled an authority receives a message to clean the bin.

\section{FUTURE ENHANCEMENT}

The proposed model can be enhanced to include an image processing module wherein it can detect human existence around the bin. This can be further used to instruct them to dispose the garbage in a better way.

\section{REFERENCES}

1. D. Hoornweg, and P. Bhada-Tata, The World Bank: What a Waste- A Global Review of Solid Waste Management, Urban Development \&amp; Local Government Unit, World Bank, 1818 H Street, NW , Washington, DC 20433 USA, 2012.

2. The Kachhra Project http://thekachraproject.in/infographic-municipal- solid-waste- msw-in- india/accessed on 2Mar- 2016.

3. Chowdhury, B., \&amp;Chowdhury, M. U. 'RFID-based Real-Time Smart Waste Management System' in Telecommunication Networks and Applications Conference (ATNAC), IEEE, pp. 175-180, 2007

4. Hannan, M. A., Arebey, M., Begum, R. A., \&amp;Basri, H. 'Radio Frequency Identification (RFID) and Communication Technologies for Solid Waste Bin and Truck Monitoring System' in Waste management, Vol. 31, Issue 12, pp. 2406-2413, 2011

5. Arebey, M., Hannan, M. A., Basri, H., \&amp; Abdullah, H. 'Solid Waste Monitoring and Management using RFID, GIS and GSM' in Research and Development (SCOReD), IEEE Student Conference, pp. 37-40, 2009

6. Rovetta, A., Xiumin, F., Vicentini, F., Minghua, Z., Giusti, A., \&amp;Qichang, H. 'Early Detection and Evaluation of Waste through Sensorized Containers for a Collection Monitoring Application' in Waste Management, Vol. 29, Issue 12, pp. 2939-2949, 2009

7. Faccio, M., Persona, A., \&amp;Zanin, G. 'Waste collection multi objective model with real time traceability data' in Waste Management, Vol. 31, Issue 12, pp. 2391-2405, 2011

8. Rajkamal, R., Anitha, V., Nayaki, P. G., Ramya, K., \&amp;Kayalvizhi, E. 'A Novel Approach for Waste Segregation at Source Level for Effective Generation of Electricity-GREENBIN' in Science Engineering and Management Research (ICSEMR), IEEE, pp. 1-4, 2014

9. Thakker, S., \&amp;Narayanamoorthi, R., 'Smart and Wireless Waste Management', in Innovations in Information, Embedded and Communication Systems (ICIIECS), pp. 1-4, 2015

10. Longhi, S., Marzioni, D., Alidori, E., Buò, G. D., Prist, M., Grisostomi, M., \&amp;Pirro, M. 'Solid Waste Management Architecture using Wireless Sensor Network Technology' in New Technologies, Mobility and Security (NTMS), 5th International Conference,IEEE, pp. 1-5, 2012

11. Al Mamun, M. A., Hannan, M. A., \&amp;Hussain, A. 'Real Time Solid Waste Bin Monitoring System Framework using Wireless Sensor Network’ in Electronics, Information and Communications (ICEIC), 